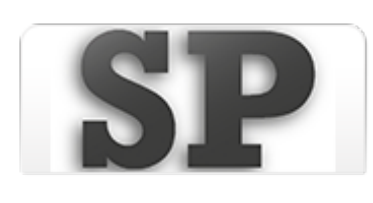

Sociedades precapitalistas ISSN: 2250-5121

publicaciones@fahce.unlp.edu.ar

Universidad Nacional de La Plata

Argentina

\title{
El Mercado de trabajo agrícola en el noreste francés (1789-1836)
}

\author{
Ríos, Manuel \\ El Mercado de trabajo agrícola en el noreste francés (1789-1836) \\ Sociedades precapitalistas, núm. 10, 2020 \\ Universidad Nacional de La Plata, Argentina \\ DOI: https://doi.org/10.24215/22505121e047
}

Atribución no comercial compartir igual (CC BY-NC-SA) 4.0 
Dossier: Formas de explotación del trabajo y relaciones laborales en sociedades preindustriales

\title{
El Mercado de trabajo agrícola en el noreste francés (1789-1836)
}

Agricultural Labor Market in Northeastern France (1789-1836)

Manuel Rios

DOI: https://doi.org/10.24215/22505121e047

Instituto de Investigaciones en Humanidades y Ciencias

Sociales, Universidad Nacional de la Plata. CONICET.

Universidad de Buenos Aires, Argentina

Recepción: 24 Mayo 2010

Aprobación: 22 Diciembre 2019

Recepción: 24 Mayo 2010

Aprobación: 22 Diciembre 2019

\begin{abstract}
Resumen:
El artículo tiene como objetivo el estudio del mercado de trabajo asalariado rural del noreste francés entre 1789 y 1836 . Mientras que los mercados de tierras o cereales ocupan un lugar destacado en la historiografía francesa, los mercados de trabajo han tendido a ser relegados en el análisis, circunscritos sobre todo a los espacios urbanos. El presente trabajo parte del análisis de mercuriales, decretos nacionales y departamentales, correspondencia y testimonios locales con el propósito de analizar las características fundamentales del mercado de trabajo agrícola y los alcances y sentidos de la política estatal de fijación de un nivel de salarios. Se insiste en la importancia de la estructura de producción rural que impone serios límites tanto a la política estatal y sus posibles regulaciones como también al desarrollo espontáneo del mercado de trabajo, polemizando así con los abordajes a la cuestión desde enfoques liberales y neoinstitucionales.
\end{abstract}

Palabras Clave: Mercado de trabajo, Estructura agraria, Salarios, Noreste francés.

\section{Abstract:}

This article aims at studying the labor market in northeastern France between 1789 and 1836 . While land or wheat markets studies have taken an important place in French historiography, labor markets have been relegated or circumscribed to urban spaces. The present work focuses in price documentation (mercuriales), national and departmental decrees, correspondence and local testimonies for the purpose of analyzing the key features of the agricultural labor market and the importance of state policies concerning wage fixation. We insist on the importance of rural production structures that impose strong boundaries upon both state policies and spontaneous development of the labor market, therefore arguing with liberal and neo-institutional approaches. KEYWORDS: Labor market, Agrarian structure, Wages, Northeastern France.

El 19 de marzo de 1794, un ignoto comisario asentado en el departamento de Moselle escribe, un tanto nervioso, una carta al presidente del Comité de Instrucción Pública. En ella manifiesta su preocupación por los efectos colaterales de los éxitos del ejército revolucionario, que para ese entonces ya pelea del otro lado de las fronteras del hexágono. "Las tropas licenciadas (...) devolverán a la sociedad unos dos millones

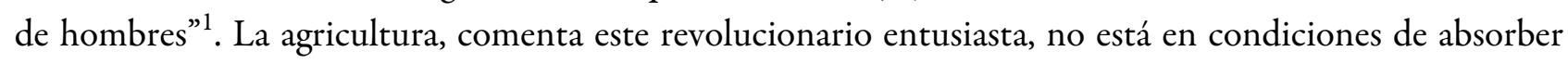
semejante caudal de mano de obra. La afirmación sorprende al historiador que fácilmente encuentra, para el siglo XVIII como también para el XIX, numerosos documentos que testimonian una realidad opuesta. En la exacta misma fecha, unos 80 kilómetros más al sur, funcionarios cantonales de Vézelise expresan, en un comunicado cargado de firmas de autoridades municipales, que el faltante de mano de obra se hace sentir con fuerza en las explotaciones rurales $(\mathrm{AN}, \mathrm{F} 10 / 320)^{2}$. Dicha queja no es nueva, la hayamos repetida en numerosos cuadernos de quejas, testimonios, tratados de agronomía, etc. (Etienne, 1930; Festy, 1947; Guérard, 1841; Godfrin, 1934; Harsany, 1946; Martin, 1928; Tessier y Bosc, 1821). A fines del XVIII, la mano de obra asalariada escasea en un país aparentemente plagado de vagabundos (Lefebvre, 1986; Duby, 1976; Jones, 1988; Goubert, 1998; Béaur, 2000). 
La historiografía ha prestado poca atención al trabajo asalariado agrícola francés en los siglos XVIII y XIX (Hubscher y Farcy, 1996). Esto es especialmente relevante, visto que, en vísperas de la Revolución francesa, la enorme mayoría de la población rural debe trabajar por un salario, tenga tierras o no. Si bien algunos progresos han sido realizados en esta área, la cuestión sigue siendo un terreno por desbrozar. El presente artículo se centra en el devenir histórico del trabajo asalariado rural en el noreste francés entre 1789 y 1836 , en particular en la región de Lorena, con el propósito de echar luz sobre numerosos interrogantes ${ }^{3}$. ¿Quiénes son los asalariados rurales franceses en los siglos XVIII y XIX? ¿Cuáles son las características del mercado de trabajo? ¿Cómo interviene el estado?

\section{Campos abiertos y distribución de la tierra}

La región de Lorena forma parte del área de campos abiertos característica del norte de Francia y Europa. Se trata de una zona cerealera, dónde el ganado constituye un apéndice indispensable a la producción agrícola. Los bienes y usos colectivos desempeñan un rol importante en la economía agrícola, los tiempos y tipos de cultivos se encuentran fuertemente regimentados por la tradición: los agricultores no son libres de cambiar la producción a su antojo (Cabourdin 1977; Ríos, 2015).

Los privilegiados constituyen, a fines del siglo XVIII, los principales propietarios de tierras. En la bailía de Mirecourt, departamento de Vosges, el clero y nobleza reúnen alrededor del 40\% de las tierras (11\% y $29 \%$ respectivamente $)^{4}$. No obstante, en la misma bailía, el campesinado se asegura una porción considerable de tierras, en torno al 39\%. La cuestión no se agota con la propiedad, puesto que los privilegiados rara vez explotan sus tierras con mano de obra asalariada. El arriendo constituye un elemento fundamental de la explotación campesina. El grueso de la tierra es labrado por el cuarto estado.

Al seno del campesinado, la tierra se distribuye de forma desigual. Los dos tercios de la propiedad campesina se concentran en un puñado de propietarios, conocidos como laboureurs, que encabezan explotaciones de más de 20 hectáreas. Sus explotaciones combinan la propiedad y el arriendo 5 . Los privilegiados optan por arrendar sus tierras en grandes trozos, inaccesibles para el grueso de los campesinos. Así, las explotaciones de más de 20 hectáreas ocupan en la bailía de Mirecourt los dos tercios del suelo ${ }^{6}$. Por otro lado, la masa, los manoeuvres, detenta propiedades de menos de una o dos hectáreas, que lejos están de ofrecer el sustento necesario para la reproducción familiar ${ }^{7}$. A fines del XVIII, la mayoría de la población lorenesa debe trabajar por un salario para sobrevivir.

\section{Trabajadores ASALARIADOS AGRícolas}

Si uno considera las posibilidades de conchabarse, a fines del siglo XVIII la oferta es múltiple. Los bosques ofrecen, en algunas aldeas, la opción de devenir leñador o incluso, forjador. Pero estas ramas son poco importantes, y el grueso del trabajo asalariado se nuclea en dos actividades: la agrícola y la textil (rural). Estas actividades no son excluyentes, el hogar del manoeuvre puede repartir las tareas para dedicarse a ambas.

Si abordamos la cuestión desde la perspectiva del manoeuvre, el carácter estacional de la producción agrícola genera tiempos muertos que permiten adoptar otras actividades durante el invierno. Además, la evaluación de los registros impositivos del Antiguo Régimen permite ver una consistente división sexual del trabajo, siendo el textil una rama ocupada por las mujeres del hogar (aunque no de forma exclusiva) ${ }^{8}$. El carácter complementario de estas actividades es relativo. En tiempos de cosecha parte de la industria (no sólo la rural) se detiene, y los trabajadores fluyen hacia los campos en busca de los altos salarios estacionales (Magnac y Postel-Vinay, 1997). Naturalmente en el origen de esta realidad se encuentran las necesidades del líder de la explotación que utiliza mano de obra asalariada, el laboureur ${ }^{9}$. Los tiempos de alta demanda de trabajadores son los de siembra (marzo, abril y septiembre), pero, sobre todo, los de la siega de los pastos (junio), la cosecha 
(julio y agosto) y posterior trilla de los cereales ${ }^{10}$. El resto del año, las necesidades de la explotación se reducen considerablemente. Por ello, la mano de obra es mixta. Una parte de los asalariados son permanentes, y se los conoce como domésticos. Contratados por un año (en Meurthe, en vísperas de la navidad), se les debe brindar un salario, techo y comida. Y en el verano, con la cosecha, la explotación contrata numerosos jornaleros asalariados. Se estima que un trabajador puede cosechar unas 20 áreas por día (Crebouw, 1986; Magnac y Postel-Vinay, 1997). La cosecha se realiza lo más rápido posible, puesto que una vez maduro el cereal, las lluvias pueden estropear todo el esfuerzo del año. En 1804, el prefecto de Meurthe, Marquis, estima que la siega, trilla y cosecha implican 400 francos (F) de gastos para una explotación de 33 hectáreas. Aquí las ecuaciones son múltiples, pero podemos proponer una estela de tres a seis trabajadores para la siega, unos diez o quince para la cosecha, y una decena o docena para la trilla ${ }^{11}$.

El carácter estacional del trabajo asalariado se sustenta en la coexistencia de las explotaciones grandes y pequeñas ${ }^{12}$. El manoeuvre, trabaja para el laboureur en los momentos de gran demanda de brazos, a cambio de un jornal ${ }^{13}$. El resto del año, su pequeña explotación y eventualmente, la industria rural a domicilio, le permiten alcanzar el ingreso necesario para la reproducción familiar (Béaur, 2016). A la par del manoeuvre micro propietario trabajan los aldeanos totalmente desprovistos de tierra, sean estos domésticos o simples jornaleros ${ }^{14}$. En Lorena, como en otras regiones de Francia, no se destaca la llegada de mano de obra golondrina: las aldeas se autoabastecen en trabajadores (Grantham, 1993).

\section{SALARIOS AGRÍCOLAS}

El salario del doméstico se fija sobre una base anual. En 1794, según una encuesta lanzada por el gobierno nacional, en Vosges un doméstico gana 87 libras tornesas por año ${ }^{15}$. En Meuse, departamento vecino, 100 libras $^{16}$. Al noroeste, en Ardennes, 128 (AN, F12/1547B). Constatamos una primera particularidad: los salarios varían considerablemente en tres departamentos aledaños. Si cruzamos estos datos con los precios, obtenemos que un doméstico en el Noreste de Francia compra uno 5,73 hectolitros de trigo por año en 1790, año de crisis. A lo largo de la década anterior, el salario permitía acceder a unos 8,50 Hl. Esto es poco, ya que a fines del Antiguo Régimen el consumo anual para una familia de cinco personas se acerca a los 30 hectolitros anuales (Labrousse, 1984; Lacoste, 1951). Mismo teniendo en cuenta que el doméstico es alimentado por el patrón, vemos que difícilmente pueda alimentar a una familia con su trabajo ${ }^{17}$.

El jornal es definido al momento de la contratación. Puede incluir el alimento (durante el tiempo de conchabo) o no, y el pago puede efectuarse en dinero o combinando dinero y especie. En Lorena domina la remuneración en dinero, aunque la retribución mixta existe. Normalmente se trata de un salario a destajo, es decir, por tarea realizada ${ }^{18}$. Y responde, naturalmente, a las variaciones en las necesidades de mano de obra de la explotación: el estipendio de verano es considerablemente más elevado que el de invierno ${ }^{19}$. En 1804, el prefecto Marquis evalúa el precio del jornal rural (masculino y sin alimento) en 1,50 F en verano, y en 1,20 F en invierno (promedio departamental). Según la misma fuente, en 1789 estos valores eran 1,20 libras en verano y 0,80 libras en invierno.

La variación estacional no es el único elemento que afecta al salario. Éste varía fuertemente de departamento a departamento. El cuadro 1 ilustra este punto.

\section{CUADRO 1}

Salario de verano del jornalero (sin alimento) en Lorena.

\begin{tabular}{|c|c|c|c|c|c|}
\hline \multicolumn{2}{|c|}{ Departamento } & Moselle & Meuse & Meurthe & Vosges \\
\hline $\begin{array}{c}\text { Salarios (en } \\
\text { libras) }\end{array}$ & 1790 & 0,6 & $1 \mathrm{a} 1,5$ & 0,8 a 1,20 & $1 \mathrm{a} 1,25$ \\
\cline { 2 - 6 } & 1793 & 1,2 & 2,5 & 2,5 & 1,8 \\
\hline
\end{tabular}


Fuente: AN F11/215; F11/221; F11/1547B; Marquis, 1804.

Si extendemos el análisis a las regiones vecinas a Lorena, encontramos el mismo fenómeno. En 1790, más al sur, en el Franco-Condado, los estipendios van de 1 libra (Jura) a 1,5 libras (Jura, Doubs). Al este, en Alsacia, rondan la libra, mientras que al oeste, en Haute-Marne (región de Champagne), 0,75 libras a 1 libra (Crebouw, 1986: 711). Con sólo recorrer entre 50 y 90 kilómetros (tomando las capitales como referencias), los salarios presentan fuertes contrastes.

CUADRO 2

Salario de verano del jornalero en Lorena y Champagne en 1804.

\begin{tabular}{|c|l|r|}
\hline \multirow{4}{*}{ Meuse } & Comunas A $^{20}$ & 1,25 \\
\cline { 2 - 3 } & Comunas B $^{21}$ & 1 \\
\cline { 2 - 3 } & Comunas C $^{22}$ & 0,9 \\
\hline \multirow{3}{*}{ Haute-Marne } & Comunas D $^{23}$ & 1 \\
\cline { 2 - 3 } & Comunas E $^{24}$ & 0,9 \\
\cline { 2 - 3 } & Comunas F $^{25}$ & 0,75 \\
\hline
\end{tabular}

Fuente: AN F10/289B.

¿Incidencia de las fronteras departamentales? En lo absoluto. Las variaciones se presentan al interior de un solo departamento, como indica el cuadro 2. Las diferencias son sensibles de una región a otra. El mapa 1 permite visualizar el fenómeno. Como vemos, no hay solución de continuidad entre las áreas de salarios altos y bajos: las diferencias salariales se distribuyen por ambos departamentos. Pero lo que también parece notarse es que, al fin de cuentas, las diferencias salariales serían mínimas en términos estadísticos: el grueso de las aldeas paga $0,75 \mathrm{~F}$ o $0,90 \mathrm{~F}$ de jornal. Sí quedaría ratificada la diferencia entre departamentos. Sin embargo, este aspecto remite más bien a una limitación de la fuente, más que a la realidad económica del noreste francés. El documento en cuestión no es un relevamiento salarial, sino la estipulación de las multas por delitos rurales, que se hace sobre la base del jornal ${ }^{26}$. Lo que la fuente permite ver es la percepción, pobre, que tienen las autoridades departamentales de una realidad salarial fragmentada. Otro aspecto relevante se percibe en la fuente, el grueso de las aldeas de salarios elevados son aldeas y ciudades densamente pobladas. ¿Una posible correlación entre demografía y salario? ¿O acaso una competencia entre la agricultura y otras tareas? 
MAPA 1

Salario de verano del jornalero sin alimento en Haute-Marne y Meuse en 1804

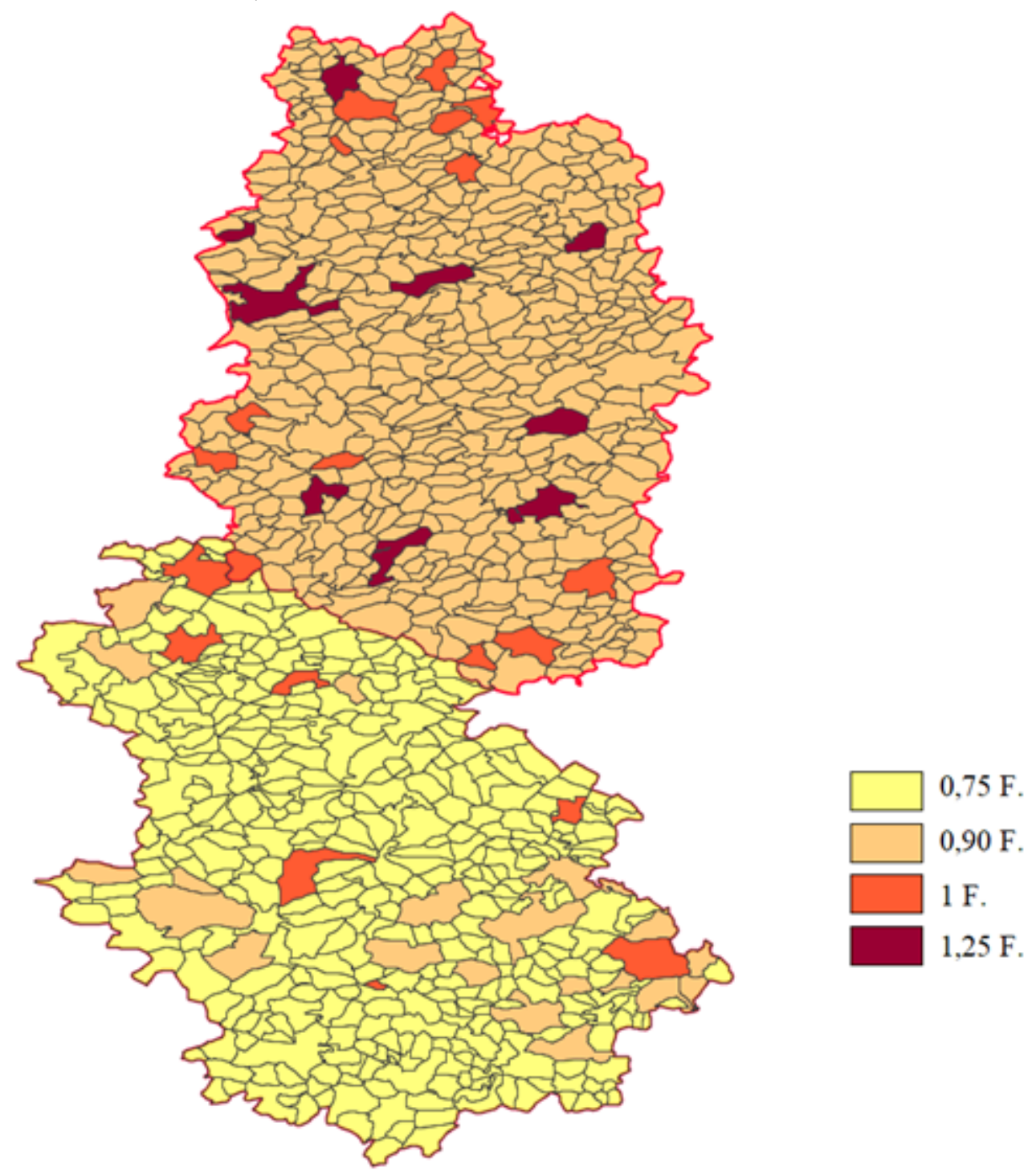

Fuente: AN F10/289B.

La documentación decimonónica, más precisa y completa, permite adentrarnos con mayor precisión en la fragmentación del salario agrícola. En 1836, el estado realiza una encuesta agrícola en la que releva, entre otros datos, el nivel de los salarios rurales. 
CUADRO 3

Salario de verano de jornalero (sin alimento) en la antigua bailía de Mirecourt en 1836.

\begin{tabular}{|c|c|c|c|c|c|}
\hline Aldea & $\begin{array}{l}\text { Jornal } \\
\text { (F) }\end{array}$ & Aldea & $\begin{array}{l}\text { Jornal } \\
\text { (F) }\end{array}$ & Aldea & $\begin{array}{c}\text { Jornal } \\
\text { (F) }\end{array}$ \\
\hline Ambacourt & 0,75 & Girecourt-les-Vieville & 0,75 & Ramecourt & 0,75 \\
\hline Baudricourt & 1 & Gironcourt & 0,75 & Remoncourt & 2 \\
\hline Bazoilles & 1,2 & Girovillers & 0,9 & Repel & 1,5 \\
\hline Bettoncourt & 1,2 & Haréville & 0,75 & $\begin{array}{l}\text { Rouvres-en- } \\
\text { Xaintois }\end{array}$ & 1,5 \\
\hline Biécourt & 0,75 & Hymont & 1,25 & Rozerotte & 1,75 \\
\hline Blemerey & 1 & Juvaincourt & 1 & Saint-Menge & 1,5 \\
\hline Boulaincourt & 1 & Ligneville & 0,75 & Saint-Prancher & 1,5 \\
\hline Chauffecourt & 1,5 & Marainville & 0,75 & $\begin{array}{l}\text { They-sous- } \\
\text { Montfort }\end{array}$ & 0,75 \\
\hline Chef-Haut & 1,5 & Mattaincourt & 2 & Thiraucourt & 0.8 \\
\hline $\begin{array}{l}\text { Domevre-sous- } \\
\text { Montfort }\end{array}$ & 1 & Mazirot & 1,2 & Totainville & 1,5 \\
\hline Domjulien & 1 & Menil-en-Xaintois & 0,75 & Villers & 1,2 \\
\hline Domvallier & 0,75 & Oelleville & 0,75 & Vittel & 1,5 \\
\hline Estrennes & 1,25 & Offroicourt & 1,5 & $\begin{array}{l}\text { Viviers-les- } \\
\text { Offroicourt }\end{array}$ & 0,75 \\
\hline FLG & 0,75 & Pont-sur-Madon & 1 & Vroville & 1,3 \\
\hline FLP & 1,2 & Poussay & 1,1 & & \\
\hline Gemmelaincourt & 1,25 & Puzieux & 0,75 & & \\
\hline
\end{tabular}

Fuente: ADV Serie M.

MAPA 2

Salario de verano de jornalero (sin alimento) en la antigua bailía de Mirecourt en 1836.

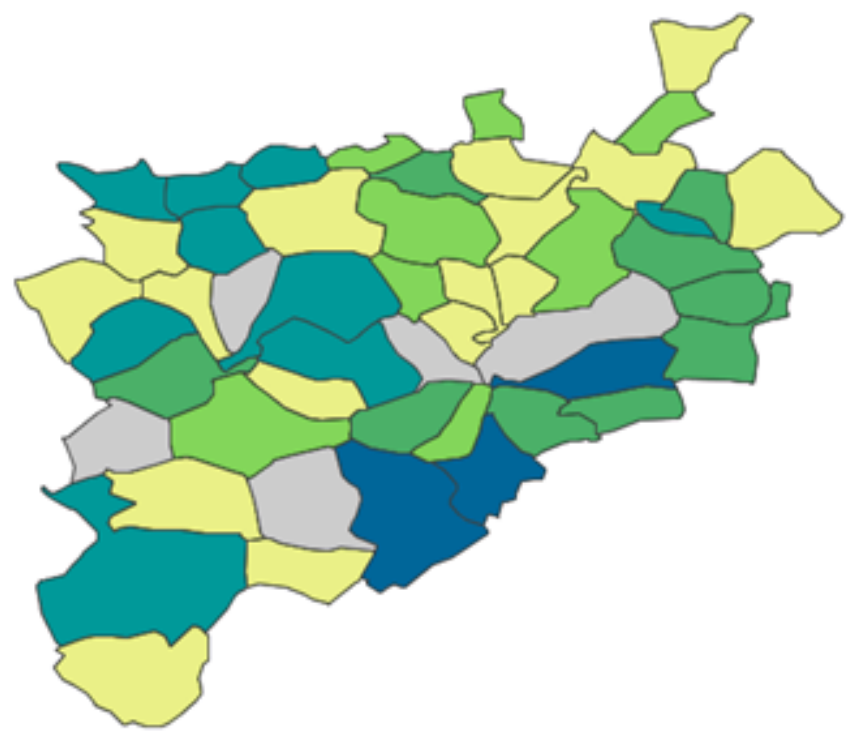

0,75 a $0,80 \mathrm{~F}$.

0,90 a $1,10 \mathrm{~F}$.

1,20 a $1,30 \mathrm{~F}$.

$1,50 \mathrm{~F}$.

1,75 a $2 \mathrm{~F}$. 
Contrastando las series salariales del siglo XIX, siglo en que despega la estadística francesa, con los valores de fines del XVIII ratificamos la crítica documental, y reafirmamos la profunda fragmentación salarial que afecta al campo francés. No sólo eso, sino que la mayor precisión documental decimonónica permite percibir una amplitud aún mayor a la que sugieren las fuentes más antiguas. En lo que fuere la antigua bailía de Mirecourt, en 1836, los salarios agrícolas oscilan entre los 0,75 F y los $2 \mathrm{~F}$. Las diferencias se dan en aldeas aledañas, situadas a entre dos y cinco km unas de otras. El mapa 2 lo retrata con claridad.

La evidencia histórica sugiere una profunda variación en los salarios agrícolas del noreste francés, que se manifiesta de departamento a departamento, de cantón a cantón, de aldea a aldea. Dicha fragmentación no es monopolio ni de una región, ni de un departamento: se expresa en todo el territorio nacional, hasta bien entrado el siglo XIX (Crebouw, 1986; Lêveque, 1996; Désert, 1996).

\section{LA ACCión DEL ESTADO}

¿Qué actitudes adopta el estado frente a esta situación? Es ampliamente conocida la acción del estado en materia de regulación de granos, no sólo en Francia o en el período moderno ${ }^{27}$. En cuanto al mercado de trabajo, célebres son las reglamentaciones vinculadas a los gremios en las ciudades hasta la Revolución, así como también resulta trillado afirmar el carácter desregulado del trabajo en el campo. A lo largo del XVIII y el XIX las intervenciones del estado son pocas: el salario es dejado a la libre negociación de los involucrados.

Empero, por más que le pese a los liberales, el libre-mercado de trabajo no parece saciar las necesidades de los productores. En los cuadernos de quejas abundan las protestas por la escasez de mano de obra. En Jevoncourt, bailía de Vézelise, departamento de Meurthe, el cuaderno postula que "la pobreza de los habitantes es la causa de la falta de obreros de todo tipo, que van al extranjero a buscar trabajo" ${ }^{28}$. Los comentarios de este tipo son habituales en los cuadernos de quejas, muchas veces asimilando el faltante al alistamiento miliciano. Por ello, se solicita que el estado prohíba el reclutamiento de los domésticos de las explotaciones agrícolas (Etienne, 1930; Godfrin 1934; Harsany, 1946; Martin, 1928). En 1793, en el departamento de Meurthe, una petición de laboureurs expone que "Dada la leva de voluntarios (...) los jornaleros y domésticos de los exponentes han partido, y desde este momento, se han quedado sin obreros, sin embargo todos son cultivadores de dos o tres arados..." ${ }^{29}$. Este tipo de peticiones son comunes en el noreste francés entre 1790 y $1794^{30}$. Ocurre que en estos años los salarios rurales crecen en términos reales, y lo hacen más rápido que los estipendios urbanos (AN, F11/215-221). Los peticionarios reclaman la acción del estado: que se prohíba el reclutamiento de domésticos, que se obligue a los domésticos de la nobleza a trabajar en los campos de los laboureurs, que se reubique a los trabajadores de la industria en las explotaciones agrícolas, o lisa y llanamente que se asigne trabajadores a las explotaciones rurales que los precisan ${ }^{31}$.

Hasta 1793, las regulaciones son escasas. En el marco de la ley Le Chapellier, que prohíbe los gremios y asociaciones colectivas, el código rural de 1791 establece la interdicción de coaligarse a los trabajadores rurales. Esto poco incide sobre el salario agrícola, que continúa subiendo. En septiembre de 1793, el estado moviliza a parte del ejército para saciar la demanda de sembradores, y a fines de ese mismo mes la ley de máximos (que establece un límite al precio del cereal), sancionada en mayo, es extendida a los salarios. Se decreta que los salarios no podrán exceder el valor de 1790 aumentado en un cincuenta por ciento. Quienes violen el decreto se exponen a tres días de prisión. El decreto busca enfriar la economía: raros son los casos en los que el salario no excede ya el valor fijado por ley (Crebouw, 1986, 1989). La ley demuestra la percepción que tiene el estado de la fragmentación del mercado de trabajo: los municipios deben establecer el monto del máximo salarial. En mayo de 1794 (11 pradial año II) la intervención estatal alcanza su zénit. En el marco del terror, se establece que todos los jornaleros, manoeuvres, y aquellos que habitualmente trabajan en la agricultura deben presentarse para la cosecha ${ }^{32}$. Se solicita a las municipalidades la elaboración de listados de obreros disponibles en cada municipio. Combinado con el máximo, este nuevo decreto pretende romper 
toda resistencia de parte de los jornaleros y domésticos, y garantizar que desempeñen sus funciones allí donde se los necesita, intentando evitar así la escalada de los salarios ${ }^{33}$. Quienes se nieguen a obedecerlo, deben ser conducidos ante el tribunal revolucionario.

A pesar de las duras medidas, el fracaso del gobierno es total. En 1794, la administración del distrito de Lamarche (Vosges) escribe a la Comisión de Comercio y Aprovisionamiento de la República que

"la apertura de la cosecha de trigo se ha realizado el 21 messidor; tres décadas han pasado; no se ha completado totalmente para los grandes arrendatarios a raíz del déficit de brazos; las de las cebadas y de las avenas a penas se han abierto, no porque aún no estén maduras, sino porque la cosecha de los trigos ha durado demasiado tiempo..." 34 .

En ese mismo año, en Moselle, los agricultores aducen la falta de mano de obra cuando se les reclama por el trigo, y el Consejo General de Metz solicita al ejército el envío de trescientos hombres para desempeñarse en la trilla, así como también otros cien hombres armados para garantizar el cumplimiento de la ley de máximos ${ }^{35}$. Pese a los decretos, la escasez de mano de obra se hace sentir en todo el noreste francés y en otras partes del territorio (Crebouw, 1986; Festy, 1947). Los productores loreneses, pragmáticos, aceptan los salarios ilegales que exigen los jornaleros (AN, F10/451, F10/452; AN F11/231, F11/379, F11/416). El comité de agricultura comenta, en un informe de octubre de 1794, que no pasa un solo día sin que llegue una consulta en torno a los medios coercitivos disponibles para la aplicación del decreto del 11 pradial (AN F10/452-453). En un primer momento, se reafirma el procedimiento ante el tribunal revolucionario. Pero eventualmente, considerando que el encierro de obreros que se resistan a aceptar el jornal fijado es contraproducente (la mano de obra que escasea, escaseará aún más), se opta por remplazar al tribunal por la policía rural, ciertamente menos dura.

El decreto de pradial no es renovado al año siguiente, y el máximo salarial es abolido (junto al de los cereales) a fines de 1794. Luego de estas experiencias, el estado no realiza grandes intervenciones sobre el mercado de trabajo al menos durante la primera mitad del siglo $\mathrm{XIX}^{36}$. En ese período, las quejas sobre la escasez de mano de obra no retroceden: el faltante de jornaleros es estructural (Guérard, 1841; Tessier y Bosc, 1821).

\section{SALARIOS, DEMOgRAFía, PROTO-INDUSTRIA Y DISTRIBUCIÓN DE LA TIERRA}

Arribamos a este último apartado con algunas constataciones. En un primer lugar, la dispersión que registra el salario agrícola francés entre 1789 y 1836. En segundo lugar, la tendencia recurrente a la escasez de mano de obra en los momentos de alta demanda. En tercer lugar, la incapacidad del estado por garantizar, a través de intervenciones varias sobre el mercado de trabajo, el abastecimiento en jornaleros de las grandes y medianas explotaciones. Finalmente, éste es igualmente incapaz de frenar las subas de los estipendios reales, a pesar de las exigencias de quienes deben abastecer el mercado de trigo, mercado neurálgico en materia económica y política en Francia (Gauthier e Ikni, 1988; Mulliez, 1979; Kaplan, 1976). Ahora sí, pese al crecimiento de los salarios reales, y pese al carácter generalizado de la escasez de mano de obra, no opera en el campo francés nivelación alguna de los salarios. Ciertamente suben, mas no se equiparan. ¿Por qué?

Naturalmente, desde la perspectiva liberal de la oferta y la demanda se desprende la posibilidad de que el salario esté determinado por la cuestión demográfica. A más población, remuneraciones más bajas. Ya constatamos en un apartado anterior que en las hinterlands de las ciudades y burgos se registran los estipendios más elevados, aunque esto también podría deberse a una mayor demanda de trabajadores, siendo que concentran una gran diversidad de actividad artesanales y, en algunos escasos casos, manufactureras. Esta es la explicación que ensaya, en parte, Pierre Lévêque (1996) para Borgoña en el siglo XIX ${ }^{37}$. Tomemos el caso de la antigua bailía de Mirecourt, bailía esencialmente rural. 
CUADRO 4

Salarios (jornalero hombre sin alimento) y población en la antigua bailía de Mirecourt en 1836.

\begin{tabular}{|c|c|}
\hline Salario (en francos) & Población promedio \\
\hline 0,75 a 0,8 & 352 \\
\hline 0,90 a 1,10 & 342 \\
\hline 1,20 a 1,30 & 295 \\
\hline 1,5 & 453 \\
\hline 1,75 a 2 & 817 \\
\hline
\end{tabular}

Fuente: ADV, Serie M.

Los promedios no permiten, por si solos, ninguna conclusión en torno a las leyes de la oferta y la demanda de trabajo asalariado. Al descomponer los promedios, encontramos que los diferentes niveles salariales se encuentran representados en todas las escalas poblacionales. Aldeas poco pobladas con salarios altos, aldeas poco pobladas con salarios bajos; lo mismo puede decirse de las aldeas muy pobladas.

Una segunda posibilidad estriba en una relativa adecuación de los precios y los salarios, es decir, estipendios más elevados allí donde el trigo es tendencialmente más caro. En 1811, el prefecto de Meurthe comenta, ante una escalada de los precios locales, que los jornales del departamento (y podemos agregar, de toda Lorena) son bajos en comparación a otros (AN F11/379). Pero, en paralelo, también son bajos los precios del trigo. Lorena es efectivamente la región de trigo más barato de Francia a fines del siglo XVIII, no obstante, sus salarios en 1790 se encuentran en el medio de la escala nacional (Labrousse, 1984; Crebouw, 1986). Por otro lado, hasta bien entrado el siglo XIX sigue funcionando el sistema de ferias y mercados (Halles), por lo que las diferentes aldeas se referencian en uno, dos o tres mercados cercanos (Margaraiz, 1988, 2015). Estos mercados, si bien no presentan un precio unificado, pese a encontrarse a unas pocas decenas de kilómetros de distancia, centralizan el comercio de numerosas aldeas. Por caso, el grueso de los productores de la antigua bailía de Vezelise (Meurthe) vende sus producciones en Nancy, Vézelise y Mirecourt. Empero, como ya vimos, los estipendios varían de aldea a aldea, mismo si éstas se referencian en los mismos mercados. La incidencia de los precios sobre los salarios debe ser, por ende, fuertemente relativizada ${ }^{38}$.

Finalmente, podrían existir desajustes desde el lado de la demanda de trabajo asalariado, lo que podría deberse a la presencia de una proto-industria rural más fuerte en algunas aldeas con respecto a otras, o en la existencia de mayores o menores posibilidades laborales en la cosecha como consecuencia de una mayor o menor concentración de la tierra (Lévêque, 1996). Con respecto a la proto-industria, nada nos permite pensar que este sería el caso. Su difusión está bastante generalizada, todos los registros impositivos permiten ver la presencia de tejedores en las aldeas rurales ( $\mathrm{ADV}$, series $\mathrm{B}$ y $\mathrm{C}$ ). En segundo lugar, el ingreso que produce el tejido es incapaz de competir contra las cosechas, que alcanzan niveles salariales más altos que los de la industria a domicilio, incluso en aquellas aldeas en que éstos son bajos. Los trabajadores de la protoindustria (e incluso, de las jóvenes y pequeñas industrias) abandonan sus puestos durante las cosechas para ir a trabajar a los campos, mejor remunerados. Durante agosto, la industria reduce considerablemente su actividad (Magnac y Postel-Vinay, 1997).

¿Qué acontece con la repartición de la tierra? La región estudiada, en su totalidad, presenta hacia 1836 una estructura social aldeana polarizada con un pequeño puñado de agricultores controlando el grueso de la superficie agrícola utilizada. En la bailía de Mirecourt, encontramos que la única variabilidad se da, no tanto en el control de la tierra por parte de explotaciones agrarias que utilizan de forma permanente mano de obra asalariada, sino más bien en el tamaño de éstas, y si se quiere, en la concentración de la toma de decisiones en menos patrones, lo que podría empujar los salarios a la baja. En 1836, la estadística releva el tamaño medio de las grandes explotaciones. 
MAPA 3

Tamaño medio de las explotaciones en la antigua bailía de Mirecourt en 1836
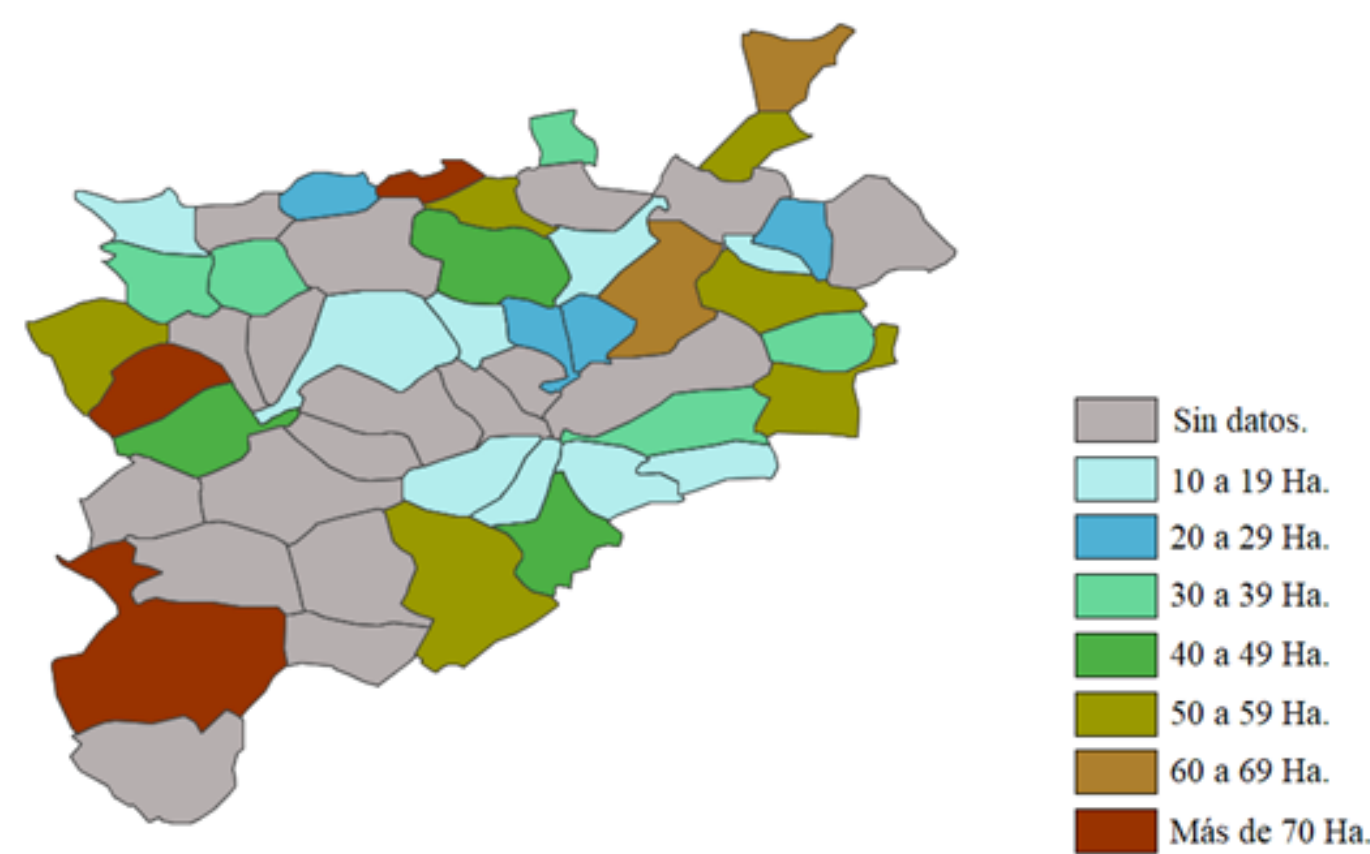

La comparación de los mapas 2 y 3 permite apreciar la ausencia de una correlación entre grandes propiedades y salarios elevados, o la inversa. Más o menos concentradas, la realidad histórica de la primera mitad del siglo XIX indica que en el noreste francés gran parte de la superficie agrícola utilizada es explotada con mano de obra asalariada. La contraparte de esta concentración de la tierra es la gran difusión de las micro explotaciones de una hectárea o menos. En la antigua bailía de Mirecourt, en 1791, los tres cuartos de los agricultores cultivan menos de una hectárea ocupando sólo el diez por ciento del suelo. Junto a los campesinos con menos de cinco hectáreas (que también deben trabajar por un salario), este porcentaje se eleva al $91 \%$ de los agricultores, que ocupan un $30 \%$ de la superficie (ADV, Fondos comunales). Con respecto a la población total, los propietarios de menos de 5 hectáreas constituyen al menos el $72 \%$ de los habitantes rurales $^{39}$. Este porcentaje debe ser tomado como un mínimo, siendo que numerosos micro tenentes no aparecen en los registros, y posiblemente la cifra sea aún más alta, entre 80 y $90 \%{ }^{40}$. En la época de elaboración de los catastros rurales (1820 a 1840), el número de propietarios de menos de 5 hectáreas ronda esos últimos valores ${ }^{41}$. El proletariado desposeído, como vemos, ocupa una porción menor de la población rural, aunque no insignificante (10 a $20 \%)$.

Es posible que la demografía o la concentración de la oferta de trabajo empujen hacia arriba o hacia abajo los salarios de los jornaleros rurales, pero en última instancia aparece como aspecto determinante de la fragmentación salarial la falta de movilidad de los factores de producción. La tierra, naturalmente, pero más aún el trabajo como resultado de la proletarización parcial del campesinado francés. Habíamos comentado que el grueso de los trabajadores proviene de las comunidades locales ${ }^{42}$. Esta mano de obra, formada en parte por jornaleros totalmente desprovistos de tierra, esta compuesta en su mayoría por micro propietarios. La tierra liga a estos trabajadores a su término, o a lo sumo, a los términos vecinos ${ }^{43}$. Siendo que la cosecha se desenvuelve en un período corto, de unas tres semanas, estos no pueden abandonar sus campos para ir a trabajar a aldeas lejanas de salarios más elevados. Por ende, no se nivelan los salarios, ni siquiera a pequeñas escalas, de pocos kilómetros de distancia, y el desabastecimiento de trabajadores en épocas álgidas deviene 
crónico. Los productores intentan, con salarios más elevados, captar a los pocos trabajadores disponibles en las comarcas vecinas. El éxodo rural, que testimonia la movilidad de la mano de obra, recién comienza a notarse en las estadísticas hacia 1850; hasta ese momento, las aldeas absorben el crecimiento demográfico (ADV, Serie M; Dupâquier, 1988). De este modo, la condición de existencia de la producción capitalista agraria, la simbiosis entre la gran y la pequeña propiedad, se convierte asimismo en el elemento que bloquea su desarrollo, y que permite comprender la escasez de mano de obra en tiempos de alta demanda ${ }^{44}$.

\section{ConCLUSIÓN}

El período analizado testimonia una profunda fragmentación del mercado de trabajo. Pero a partir de la segunda mitad del siglo XIX, las diferencias salariales tienden a matizarse (Baudin, 1992b; Crebouw, 1986; Désert, 1996; Ministère de l'Agriculture, 1897). En Lorena, como en el resto de Francia, la red ferroviaria debe haber jugado su papel, aunque cabe remarcar que el desarrollo del entramado regional data del último cuarto de siglo. Algunas décadas antes, desde 1850, se multiplica la demanda de trabajo asalariado permanente en la minería de hierro, la siderurgia y la metalurgia, sectores económicos fundamentales de la "Lorena de hierro" de la segunda mitad de siglo; mientras tanto, el textil continúa su crecimiento ${ }^{45}$.

En el campo, en el período 1789-1836, las estructuras de una economía de transición aún perduran. En términos de Marx (2011) el noreste francés de la primera mitad del siglo XIX evidencia un avanzado proceso de subsunción formal del trabajo al capital. Los productores directos (manoeuvres) distribuyen su trabajo entre sus escasas parcelas y las tierras de los laboureurs, desempeñando en ambas las exactas mismas funciones: no ha operado ninguna revolución del proceso productivo. Como en siglos anteriores, la pequeña propiedad y los bienes y usos colectivos combinados con el trabajo asalariado ofrecen a los manoeuvres la posibilidad de subsistir. Asimismo, al fijar la mano de obra en la aldea, permite a los laboureurs obtener trabajadores para los momentos de los grandes trabajos, y licenciarlos en el invierno. Hasta 1850 se registra entonces una escasa movilidad de los trabajadores, lo que frena cualquier nivelación de los salarios agrícolas. Ante esto, el accionar del estado es inútil. Contrariamente a los postulados de la escuela neoinstitucionalista, los cambios institucionales impulsados por la Revolución tienen, en esta área, poca incidencia (Lepage, 1978; North y Thomas, 1991; Rosenthal, 1992). El despegue económico de la segunda mitad del siglo XIX se cimenta en elementos de transformación estructural. En Lorena, el crecimiento demográfico, la concentración de la tierra, la progresiva destrucción de los bienes y usos comunales y el despegue industrial crean las condiciones para una mayor movilidad de las personas (Baudin, 1992a, 1992b; Contamine, 1932; Duby, 1976; Ríos, 2015). No obstante, la evolución del campo lorenés en el siglo XIX permite interrogarse sobre los límites que ofrece el capitalismo agrario como motor de la subsunción real del trabajo al capital. Hacia fines de siglo el lugar del trabajo asalariado retrocede pese a que la concentración de tierras continúa su ritmo (Hubscher y Farcy, 1996; Mayaud, 1996, Crebouw, 1986). Al menos en Lorena, ese papel lo ocupará, desde 1850, la industria.

\section{RefERENCiAS}

Amaral, S. (1987). Trabajo y trabajadores rurales en Buenos Aires a fines del siglo XVIII. Anuario IEHS, 2, pp. $33-41.42-52$.

Astarita, C. (1997). Dinámica del sistema feudal, marginalidad y transición al capitalismo. En Vaca Lorenzo, A. (Ed.). Disidentes, heterodoxos y marginados en la historia (pp. 21-49). Salamanca: Ediciones Universidad de Salamanca.

Astarita, C. (2005). Del feudalismo al capitalismo. Cambio social y politico. Castilla y Europa occidental, 1250-1520. Valencia: Universidad de Valencia.

Baudin, F. (1992a). Histoire économique et sociale de la Lorraine. L'essor. Nancy: Presses Universitaires de Nancy. 
Baudin, F. (1992b). Histoire économique et sociale de la Lorraine. L'essor. Nancy: Presses Universitaires de Nancy.

Béaur, G. (2000). Histoire agraire de la France au XVIIIe siècle. Paris: SEDES.

Béaur, G. (2016). Tierra, trabajo y relaciones sociales en la Francia de la Edad Moderna y de comienzos de la Época Contemporánea (siglos XVI-XIX). En García González, F., Béaur G. y Boudjaaba, F. (eds.), La historia rural en España y Francia (Siglos XVI-XIX). Contribuciones para una historia comparada y renovada. Zaragoza: SEHA.

Bloch, M. (1931). Caractères originaux de l'histoire rurale française, Paris: Les Belles lettres.

Cabourdin, G. (1977). Terre et Hommes en Lorraine. 1550-1663. Nancy: Université de Nancy.

Chevet, J. M. (1998). La Terre et les Paysans en France et en Grande-Bretagne. Du début du XVIIe siècle à la fin du XVIIIe siècle. Paris: Messene.

Chevet, J.-M. y Saint-Amour, P. (1991). L'intégration des marchés du blé en France au XIXe siècle. Histoire \& Mesure, 6(1/2), pp. 93-119.

Clark, K. (1990). The Roots of Rural Capitalism. Western Massachusetts 1780-1860. Ithaca: Cornell University Press.

Clère, J. J. (1988). Les paysans de la Haute-Marne et la Révolution Française. Paris: Éditions du C.T.H.S.

Colombo, O. (2009). El funcionamiento de los mercados campesinos medievales. Regulación política e intercambio desigual en la Baja Edad Media (Castilla, 1250-1520) (Tesis doctoral). Universidad de Buenos Aires, Buenos Aires.

Contamine, H. (1932). Metz et la Moselle de 1814 à 1870. Etude de la vie et l'administration d'un département au XIXe siècle. Nancy: Société d'impressions typographiques.

Crebouw, Y. (1986). Salaires et salariés agricoles en France des débuts de la Révolution aux approches du XXe sie\#cle (Tesis Doctoral). Paris Université 1, Paris.

Crebouw, Y. (1989). Les salariés agricoles face au Maximum des salaires. En Bousset, J.-C., Vovelle, M., Aberdam, S., Ormières, J.-L., Pelzer, E., Duma, J.,... Lemarchand, G., La Révolution Française et le monde rural (pp.113-122). Paris: C.T.H.S.

Désert, G. (1996). Les salariés agricoles en Basse-Normandie au XIXe siècle. En Hubscher, R. y Farcy, J.-C., La moisson des autres. Les salariés agricoles aux XIXe et XXe siècles (pp. 103-123). Saint-Paul: CREAPHIS.

Duby, G. (1975). Histoire de la France rurale, Paris: Seuil.

Dupâquier, J. (1988). Histoire de la population française. De 1789 à 1914. Paris: Presses Universitaires de France.

Festy, O. (1947). Les conditions de productions de céréales. Paris: Gallimard.

Garavaglia, J. C. (1987). ¿Existieron los gauchos? Anuario IEHS, 2, pp. $42-52$.

Gauthier, F. e Ikni, G.-R. (1988). La guerre du blé au XVIIIe siècle. La critique populaire contre le libéralisme économique au XVIIIe siècle. Paris: Éditions de la passion.

Gauthier, F. (1977). La voie paysanne dans la révolution française. L'exemple de la Picardie, Maspero, París.

Gayot, G., Hirsch, J.-P., Perrot, J.-C., Chassagne, S., Bart, J., Woronoff, D.,... Bergeron, L. (1989). La Révolution française et le développement du capitalisme. Lille: Université de Lille.

Gelman, J. (1987). ¿Gauchos o campesinos? Anuario IEHS, 2, pp. 53-60.

Goubert, P. (1998). Paysans du XVIIe siècle en Beauvaisis : laboureurs et manouvriers. En Béaur, G. (Ed.), La terre et les hommes. France et Grande-Bretagne. XVIIe-XVIIIe siècle (pp. 33-50). Paris: Hachette.

Grantham, G. W. (1993). Agricultural Productivity and Occupational Specialization in Pre-Industrial France. The Economic History Review, 46 (3), pp. 478-502.

Hubscher, R. y Farcy, J.-C. (1996). Introduction. En Hubscher, R. y Farcy, J.-C., La moisson des autres. Les salariés agricoles aux XIXe et XXe siècles (pp. 5-11). Saint-Paul: CREAPHIS.

Jacquet, A. (1998). La terre, la charrue, les écus. La société villageoise de la plaine thermale des Vosges de 1697 à 1789. Nancy: Presses universitaires de Nancy.

Jessenne, J.-P. (1987). Pouvoir au village et Révolution. Artois 1760-1848. Lille: Presses Universitaires de Lille.

Jones, P. (1988). The Peasantry in the French Revolution, Cambridge: Cambridge University Press. 
Kaplan, S. L. (1976). Le Pain, le peuple et le roi: la bataille du libéralisme sous Louis XV, Paris: Perrin.

Kaplan, S. L., Minard, P. (2004). La France, malade du corporatisme. XVIIIe-XXe siècles. Paris: Belin.

Kautsky, K. (2013). La cuestión agraria. México: Siglo XXI.

Kritsman, L. N. (1984). Class stratification of the Soviet Countryside. The Journal of Peasant Studies, 11 (2), pp. $85-143$

Labrousse, C.-E. (1984). Esquisse du mouvement des prix et des revenus en France au XVIIIe siècle. Paris: Editions des archives contemporaines.

Lacoste, M. (1951). La crise agricole dans le département de la Meurthe à la fin de l'Ancien régime et au début de la Révolution (Tesis Doctoral). Université de Nancy, Nancy.

Lefebvre, G. (1986). El Gran Pánico de 1789. Barcelona: Paidós.

Leon, P. (1980). Historia económica y social del mundo. La dominación del capitalismo: 1840-1914. Madrid: Encuentro.

Lepage, H. (1978). Demain le capitalisme. Paris: Pluriel.

Lévêque, P., (1996). Les salariés agricoles en Bourgogne au milieu du XIXe siècle. En Hubscher, R. y Farcy, J.-C., La moisson des autres. Les salariés agricoles aux XIXe et XXe siècles (pp. 77-102). Saint-Paul: CREAPHIS.

Magnac, T. y Postel-Vinay, G. (1997). Wage-competition between Agriculture and Industry in Mid-Nineteenth Century France. Explorations in Economic History, 24, pp. 1-26.

Margaraiz, D. (1988). Foires et marchés dans la France préindustrielle. Paris: EHESS.

Margaraiz, D. (2015). Institutions et espaces de marché: de l'abstrait au concret. En Bayard, F., Fridenson, P. y Rigaudière, A., Genèse des marchés (pp. 49-65). Paris: Comité pour l'histoire économique et financière de la France.

Marx, K., (2011). El capital. Libro I. Capitulo VI (inédito). México: Siglo XXI.

Mayaud, J.-L., (1996). Salariés agricoles et petite propriété dans la France du XIXe siècle. En Hubscher, R. y Farcy, J.C., La moisson des autres. Les salariés agricoles aux XIXe et XXe siècles (pp. 29-55). Saint-Paul: CREAPHIS.

Mayo, C. (1987a). ¿Una campaña sin gauchos? Anuario IEHS, 2, pp. 61-70.

Mayo, C. (1987b). Sobre peones y malentretenidos: el dilema de la economía rural rioplatense durante la época colonial. Anuario IEHS, 2, pp. 25-32.

Mulliez, J. (1979). Du blé, "Mal nécessaire". Réflexions sur les progrès de l'agriculture de 1750 à 1850. Revue d'histoire moderne et contemporaine, 26 (1), pp. 3-47.

North, D. y Thomas, R. P. (1991). El nacimiento del mundo occidental. Una nueva historia económica (900-1700). Madrid: Siglo XXI.

Postel-Vinay, G. (1974). La rente foncière dans le capitalisme agricole. Paris: Maspero.

Poull, G. (1997). Les fondateurs de l'industrie textile vosgienne 1800-1870. Histoire d'une classe sociale en voie de développement. Metz: Serpenoise.

Prêcheur, C. (1959). La Lorraine sidérurgique. Paris: S.A.B.R.I.

Ribeill, G. (1984). Aspects du développement du réseau ferré français sur la longue durée. Cabier/Groupe Réseaux, 1, pp. 10-25.

Ríos, M. (2014). Poder político, programa y pasturas en Lorena en vísperas de la Revolución Francesa. Anuario de la Escuela de Historia de la Facultad de Humanidades y artes de la Universidad Nacional De Rosario, 26, pp. 177-201.

Ríos, M. (2015). Programas políticos y bienes y usos comunales en Lorena durante la Revolución Francesa. Sociedades Precapitalistas, 4 (2).

Rosenthal, J.-L. (1992). The Fruits of Revolution. Property rights, litigation, and French agriculture, 1700-1860. Cambridge: Cambridge University Press.

Vivier, N. (2005). Ruralité française et britannique. XIIIe-XXe siècles. Approches comparées. Rennes: Presses Universitaires de Rennes.

Woronoff, D. (1998). Histoire de l'industrie en France: du XVIe siècle à nos jours. Paris: 1998. 


\section{DOCUMENTACIÓN EDITADA:}

Etienne, C. (1930). Cahiers de doléances des Bailliages des Généralités de Metz et de Nancy pour les Etats Généraux de 1789. Nancy: Berger-Vernault.

Godfrin, J. (1934). Cahiers de doléances des bailliages des généralités de Metz et de Nancy pour les États Généraux de 1789, Paris: Ernest Leroux.

Harsany, Z. E. (1946). Cahiers de doléances des Bailliages des Généralités de Metz et de Nancy pour les Etats Généraux de 1789. Paris: Paul Hartman.

Guérard, J. D. (1841). Annales agricoles de la Lorraine depuis Gérard d'Alsace jusqu'à nos jours. Nancy: Grimblot, Raybois et compagnie.

Marquis, J. J. (1804). Mémoire statistique du département de Meurthe. Paris: Imprimerie impériale.

Martin, E. (1928). Cabiers de doléances du bailliage de Mirecourt. Épinal: Imprimerie lorraine.

Mathieu de Dombasle, C.-J.-A. (1821). Le calendrier du bon cultivateur ou manuel de l'agriculteur praticien. Nancy: Haener.

Ministère de l'Agriculture (1897). Statistique agricole de la France. Paris: Imprimerie Nationale.

Tessier, M., Bosc, M. (1821). Annales de l'agriculture française, Paris: Huzard.

\section{Notas}

1 “Les troupes licenciées (...) rendront à la société environ deux millions d'hommes”. Archives Nationales (AN), F10-331.

2 En 1789-1790 se redibujan las fronteras internas del reino de Francia. El país es divido en departamentos, éstos en distritos, y éstos últimos, a su vez, en cantones. Los campesinos acomodados están bien representados en la administración de estos últimos y más aún en los municipios, que controlan (Ríos, 2014).

3 En 1789, la región histórica de Lorena es dividida en cuatro departamentos: Moselle, Meuse, Meurthe y Vosges.

4 La bailía constituye una unidad administrativa del Antiguo Régimen. La bailía de Mirecourt, situada al norte de lo que luego sería el departamento de Vosges, está conformada por unas cincuenta aldeas. Archives départementales des Vosges (ADV), Fondos Comunales.

5 El elemento distintivo del laboureur no es la superficie de la que es propietario, sino más bien la posesión del arado y los animales de tiro necesarios para la explotación de grandes superficies (Bloch, 1931).

6 Esta realidad se extiende a gran parte del noreste francés (Clère, 1988; Cabourdin, 1977; Duby, 1976; Gauthier, 1977; Ríos, 2015).

7 Se estima que para reproducir a una familia se precisan unas 6 a 12 hectáreas, dependiendo de la naturaleza del cultivo (menos para el caso de las viñas), la fertilidad, y el número de personas a alimentar (Chevet, 1998; Jacquet, 1998).

8 Los registros impositivos arrojan silencios considerables en torno a las mujeres, ya que es el jefe de familia el que aparece mencionado. Pero las mujeres jóvenes no casadas, así como las viudas, deben pagar impuestos. Entre ellas, el dominio de la actividad textil es evidente (ADV, Series B y C; Vivier, 2005).

9 Tomamos como referencia de la explotación con mano de obra asalariada las 20 hectáreas. Si bien es posible que las explotaciones de más de 15 e incluso 10 hectáreas también la utilicen, el tamaño de la prole y las características del suelo inciden fuertemente en esta franja comprendida entre las 10 y las 20 hectáreas. Ahora sí, no cabe ninguna duda de que las explotaciones de más de 20 hectáreas utilizan trabajadores asalariados.

10 Mientras que una parte notable de la tierra está sometida al régimen de rotación trienal (trigo, avena y barbecho), una porción del suelo que en Lorena tiende a oscilar entre el 10 y el $25 \%$ de la superficie agrícola utilizada escapa a este sistema. Se trata de las praderas naturales, propiedad privada que es segada en junio. Luego de la siega, estas tierras se abren al pastoreo del rebaño comunal, que puede permanecer en ellas hasta marzo, cuando son cerradas nuevamente. Se trata del régimen de derrota de mieses (Cabourdin, 1977).

11 Estas cifras deben ser tomadas como indicativas, de ningún modo consisten en cifras exactas. El tiempo, las necesidades y la disponibilidad de liquidez determinan cuántos trabajadores se conchaban. Los agrónomos ilustrados sugieren el mayor numero posible para cosechar cuanto antes (Mathieu de Dombasle, 1821). Nótese que estas tareas se suceden en el tiempo. Si bien la trilla puede solaparse con la cosecha, las tiranías del tiempo urgen a que la primera comience una vez terminada la segunda. 
12 Fenómeno que lejos está de ser exclusivamente francés. Articulaciones similares se perciben en realidades cercanas como Alemania, o distantes como Argentina o Estados Unidos (Amaral, 1987; Clark, 1990; Garavaglia, 1987; Gelman, 1987; Kautsky, 2013; Mayo, 1987a, 1987b; Postel-Vinay, 1974).

13 Su retribución, estimada en dinero, puede también ser reemplazada por el labrado de su microparcela. El manoeuvre no tiene ni arado ni animales de tiro. Sólo puede labrar su tierra con la ayuda del arado del laboureur. Este intercambio de servicios constituye, según Kritsman (1984), una relación salarial encubierta.

14 Una porción no menor de la aldea virtualmente no posee tierra. Los derechos colectivos, el pequeño jardín de la casa, la industria rural y el trabajo agrícola estacional los mantienen al interior de la comunidad, aunque pueden tener que mendigar parte del año. En ocasiones, los registros impositivos permiten reconocerlos (ADV, series B y C; Astarita, 2005; Duby, 1976).

15 Nos referimos al doméstico hombre que no recibe alimento como complemento de pago. Si bien las mujeres también trabajan en los campos, por salarios más bajos, el presente estudio tomará como referencia el salario del hombre no alimentado, siendo éste el caso más frecuente de trabajador agrícola.

16 En 1795 la libra tornesa (moneda más difundida en el reino) es reemplazada por el Franco. Una libra tornesa equivale a 0,987 francos, por lo que, a la hora de la conversión, las cifras nominales son virtualmente idénticas. A continuación, toda referencia a la libra remite a la libra tornesa.

17 Si bien el doméstico tiende a ser joven y no estar casado, hay casos en los que lo está. El trabajo femenino deviene imprescindible para sostener una familia.

18 En otras regiones, el jornal, como su nombre lo indica, refiere a una jornada de trabajo, independientemente de la conclusión o no de la tarea (Baudin, 1992a; Cabourdin, 1977; Crebouw, 1986).

19 No es sólo una cuestión de demanda y oferta de trabajadores, también hay que destacar que el verano extiende considerablemente la jornada laboral, que pasa de unas ocho horas en invierno a unas 14 horas en verano (Crebouw, 1986).

20 Bar-sur-Ornain, Clermont, Commercy, Etain, Ligny, Stenay, Saint-Mihiel, Varennes, Verdun.

21 Ancerville, Damvillers, Dun, Gondrecourt, Jametz, Laheycourt, Marville, Montmédy, Mouzay, Revigny, Vaucouleurs, Vavincourt.

22 Resto del departamento.

23 Bourbonne, Bourmont, Chaumont, Joinville, Langres, Saint-Dizier, Wassy.

24 D'Arc-en-Barrois, Breuvannes, Bussières-les-Belmont, Coiffy-le-Haut, Éclaron, Fays-Billot, Fresnes-sur-Apance, Hortes, La Feté-sur-Aube, Melay, Montigny, Montier-en Der, Neuilly-les-Langres, Nogent, Orges, Poissons, Rollampont, Serqueux, Varennes, Ville-Sur-Aujon, Voisey.

25 Resto del departamento.

26 Los delitos rurales conllevan una determinada pena estimada en jornadas de trabajo, pero pagada en dinero.

27 En 1774, la liberalización del comercio de granos impulsada por Turgot deriva en una enorme revuelta popular, a veces presentada como antecedente directo de la Revolución. La lección que deja al gobierno, tanto monárquico como revolucionario, es clara: el estado no puede abandonar el control del precio del cereal (Astarita, 2005; Colombo, 2009; Gauthier e Ikni, 1988; Gayot, Hirsch, Perrot, Chassagne, Bart, Woronoff... Bergeron, 1989; Kaplan, 1976; Kaplan y Minard, 2004; Thompson, 1984)

28 "La pauvreté des habitants est cause de la disette des ouvriers en tout genre, qui vont chez l'étranger chercher de l'ouvrage." (Etienne, 1930: 215).

29 En Lorena, la expresión "dos o tres arados" constituye una metonimia que designa la extensión de la explotación. Como referencia, puede decirse que cada arado representa unas 24 hectáreas. “ Due la levée des volontaires (...) les garçons et domestiques des exposants sont party [sic], et de ce moment, ils sont resté [sic] sans ouvriers, cependant tous sont cultivateurs de deux ou trois charrues..." (AN F10/285).

30 También aparecen en otras regiones de Francia (Festy, 1947). Crebouw (1986) relativiza la incidencia de la leva sobre el nivel de los salarios.

31 Véase AN F10/289BF10/320, F10/451, F10/452, F10/453, F11/215, F11/221, F11/379, F11/416; Crebouw, 1989; Festy, 1947.

32 En septiembre, dicho decreto es extendido a los trilladores, pero con un aumento del setenta y cinco por ciento sobre el salario de 1790.

33 Una carta del distrito de Arnay, departamento de Doubs (Franco-Condado) sugiere que los obreros parten hacia las zonas de salarios más elevados. El decreto de pradial pretende limitar esta práctica. No hemos encontrado quejas en este sentido de los administradores loreneses (AN F10/451).

34 "L'ouverture de la moisson des bleds s'est faite au 21 messidor ; trois décades sont écoulées ; on n'en a pas totalement finie $[s i c]$ pour les gros fermiers à raison du défaut de bras; celles des orges et des avoines s'ouvrent à peine, non parce qu'ils ne sont pas mûrs ; mais parce que la récolte des bleds a duré trop longtemps...” (AN F11/416). 
35 Desconocemos el resultado de dicha demanda. En general, el gobierno insiste en que el mecanismo para garantizar el cumplimiento de la ley es el tribunal revolucionario, no la presencia militar (AN F10/452-453).

36 La cota AN F10/289 presenta numerosas piezas en las que las autoridades departamentales de Meuse, Meurthe y HauteMarne establecen el valor del jornal (diferenciado) para todo el departamento durante la Revolución y el Imperio. Sin embargo, estos decretos son estrictamente administrativos, y tienen como intención establecer el valor monetario que sirve de base a las penas judiciales, como ya explicamos en una nota anterior. En ningún momento se pretende llevar esta resolución a la realidad del mercado de trabajo, como cree Baudin (1992a).

37 Como Désert (1996), Lévêque (1996), además de considerar la cuestión demográfica y la competencia de la industria, hace enorme énfasis en la incidencia de la riqueza de una determinada región a la hora de pagar salarios elevados. Esto supone dos problemas. En primer lugar, el mismo Lévêque reconoce que esto no se valida en todos los casos por él trabajados. En segundo lugar, parte de los promedios de cada arrondissement (reemplazan en 1799 a los distritos), lo que nubla las diferencias inter parroquiales. Mirecourt, región rica del departamento de Vosges, expresa variaciones muy fuertes de aldea en aldea. Désert, por su parte, sólo trabaja con los promedios departamentales.

38 Lo mismo puede ser dicho sobre la red vial. Muy pobre hasta 1830, difícilmente pueda explicar la diferencia salarial inter aldeana (Leon, 1978).

$3952 \%$ de los habitantes de la bailía tiene menos de una hectárea, mientras que el $20 \%$ es propietario de entre 1 y 5 hectáreas (ADV, Fondos comunales).

40 Para el departamento de Haute-Marne en vísperas de la Revolución, Jean-Jacques Clère (1988) estima que un 18 o 20 $\%$ de la población consiste en proletarios totalmente desposeídos.

41 Entre 60 y $75 \%$ los propietarios de menos de una hectárea, y en torno al $20 \%$ los propietarios de una a cinco hectáreas (ADV, Serie P).

42 Kautsky (2013) destaca la importancia que tiene la pequeña propiedad en el abastecimiento de la mano de obra de las grandes explotaciones, y considera que allí donde desaparece la pequeña explotación, la grande queda jaqueada.

43 Esta es la opinión del prefecto del departamento de la Meurthe a comienzos del siglo XIX (Marquis, 1804).

44 Carlos Astarita $(1997,2005)$ estima que el verdadero sostén de las relaciones sociales de producción capitalistas en el contexto de la transición castellana lo componen los trabajadores parcialmente desposeídos, y no tanto (aunque sí en parte) los vagabundos y errantes totalmente desposeídos que, desligados de las comunidades, son difícilmente disciplinados y, agregamos, representan un elemento inestable en los cálculos del productor proto-capitalista. El campesino micro propietario, al estar integrado a la comunidad, se ve sometido a los mecanismos de control y coerción política que ejerce la élite aldeana. En Francia, a fines del Antiguo Régimen, percibimos la misma autoridad política a nivel de las aldeas (Jessenne, 1987; Ríos, 2014).

45 El textil conserva su carácter domiciliario. Hacia fines de siglo XIX se percibe el avance de la concentración fabril (Baudin, 1992b; Chevet y Saint-Amour, 1991; Leon, 1978; Prêcheur, 1959; Poull, 1983; Ribeill, 1984; Woronoff, 1998)

\section{BY-NC-SA}

